\title{
Shifts of Cohesive Devices in English-Chinese Translation
}

\author{
Jing $\mathrm{Wu}$ \\ School of Foreign Languages, Qingdao University of Science and Technology, China
}

\begin{abstract}
This paper explores shifts of cohesive devices in translating English texts into Chinese based on the framework of Halliday and Hasan's cohesion theory, regarding the different preferences for cohesive devices in the two languages and strategies adopted in the shifting process. In the meanwhile, the underlying causes contributing to the differences in cohesion are explored from the perspective of the two distinct language differences, namely topic-prominence and subject prominence; parataxis and hypotaxis. Several English texts and their corresponding ones in Chinese are analyzed to achieve these goals.
\end{abstract}

Index Terms - cohesion, topic-prominence, subject-prominence, hypotaxis, parataxis

\section{INTRODUCTION}

Chinese and English are markedly different languages due to the fact that they have developed largely in separation from each other. The application of cohesive devices is one of the most distinguishing features between them. While usually considered a predominantly hypotactic language, English puts great importance on the cohesive means to connect sentence components together; Chinese is usually considered a predominantly paratactic language which relies more on semantic meaning rather than cohesive devices to achieve coherence. The difference in the application of cohesive devices makes it necessary to reconstruct cohesive relations in the E-C translation in order to achieve coherent text. As is pronounced by Peter Newmark (1987) that the topic of cohesion has always been "the most useful constituent of discourse analysis or text linguistics applicable to translation. (p.295). During the translation process, equipped with the knowledge of similarities and more importantly differences in cohesive devices, translators will be able to understand the original text better and accurate and they are able to shift cohesive devices in the target language so as to achieve the corresponding semantic effects. Thus, it is of great value to make a comparative study of the cohesive devices.

According to Halliday and Hasan(1976), cohesion refers to "relations of meaning that exist within the text and that define it as text" (p.4) In other words, a text is integrated by elements through the use of cohesive devices. Halliday and Hasan explain how cohesion is realized in a text: "Cohesion occurs where the INTERPRETATION of some elements in the discourse is dependent on that of another. The one PRESUPPOSES the other, in the sense that it cannot be effectively decoded except by recourse to it. When this happens, a relation of cohesion is set up, and the two elements, the presupposing and the presupposed, are thereby at least potentially integrated into a text."(ibid) In this book, they classified cohesive devices into five categories: reference, substitution, ellipsis, conjunction, and lexical cohesion, which will be explored one by one so as to find the differences in the way the two languages realize cohesion in hope to provide solutions to the reconstruction of cohesive devices in English-Chinese translation.

\section{DifFERENCES WITH RESPECT TO REFERENCES}

According to Hadley, I.L. (1987), "reference is concerned with the identification of a thing, or specific group of things, by the use of certain reference items, such as personal pronouns. As these items appear in the text for the second or more times, they establish a network of meaning between the various sections of the discourse." Reference is sentence elements that "instead of being interpreted semantically in their own right, make reference to something else for their interpretation (Halliday \& Hasan 1976, p.30). It can be divided into the following three types: personal, demonstrative and comparative. English personal pronouns take different forms depending on number (usually singular or plural), grammatical or natural gender and case, while Chinese pronouns do not take inflected forms to indicate its case. For instance, in Chinese, there is neither distinction between pronouns served as the subject or object of a sentence nor in the possessive adjective and possessive pronoun; both are formed by appending the particle “的”. And possessive pronouns are often omitted in Chinese if they are not used for indicating the ownership, which is a common feature of the language. Besides, there is only one plural form "they (their, them)" in English which refers to things both animate and inanimate. In Chinese, however, the plural forms of the third persons are used in a more complicated way because they are distinguished by the human genders, and so does their singular forms. Meanwhile, the suffix “们” is added after the singular personals in the formation of the plural forms, like “他们” refers to those who are male or neutral; “她 们”, those feminine; “它们”, those neutral. Furthermore, the personal reference items in English can often be used both anaphorically and cataphorically. However, they are seldom used cataphorically in Chinese. Therefore, the personal 
reference should be converted from cataphoric to anaphoric in E-C translation.

From the above statements can be concluded that the differences of personal reference items is something more concerns with the form than meaning which are easy to identify and deal with in translation, however, there are differences, important but easily to be overlooked in translation. That is, in English anaphoric pronouns are used extensively, and zero anaphors are grammatically constrained (Chomsky: 1981). But in Chinese, the use of anaphoric pronouns is much less extensive and the use of zero anaphors is pervasive. Much of the use of zero anaphors in Chinese can be accounted for by Chinese being a topic-prominent language. According to Charles N. Li and Sandra A. Thompson (1981), languages may differ in their strategies in construction sentences according to the prominence of the notions of topic and subject. And Chinese is a typical topic-prominent language. According to Zhao Yuanren(1979, p.45), "in Chinese, the proportion of applicability of the actor-action meanings is still very low, perhaps not much higher than 50 percent and wider conception of topic and comment is much more appropriate". A phenomenon related to this topic-comment construction is topic chain, "where a referent is referred to in the first clause, then their follow several more clauses talking about the same referent but not overtly mentioning that referent (Li and Thompson, 1981, p.659). In other words, once the topic is established at the beginning of the sentence, it can be omitted from the rest of the clauses, because the topic has a semantic control over the whole sentence. Due to this, in E-C translation, referents are often dropped out if they refer to something already brought up in the sentence.

Example 1

ST : So if a man's wit be wandering, let him study the mathematics; for in demonstrations, if his wit be called away never so little, he must begin again. (cited from Of Study)

TT: 如智力不集中, 可令读数学, 盖演算须全神贯注, 稍有分散即须重演。(translated by Wang Zuoliang)

In the English translation, "a man" is followed by a number of occurrences of "him", "his" and "he" which constitutes the internal cohesion of the sentence. In contrast, in the Chinese translation, all the personal references whether they server as a subject or object are omitted, but it is grammatically correct and semantically clear and concise because they are about the same topic.

There is also another important difference that lexical repetition is extensively used in Chinese where reference is frequently used in English. Thus, it is fine if the personal and the demonstrative reference in English are converted into the repetition of the same word in Chinese.

Example 2:

ST: Crafty men contemn studies, simple men admire them, and wise men use them, for they teach not their own use; but that is a wisdom without them and above them, won by observation. (cited from Of Study)

$\mathrm{TT}$ : 狡點者鄙读书，无知者羡读书，唯明智之士用读书，然书并不以用处告人，用书之智不在书上，而在书 外, 全凭观察得之。(translated by Wang Zuoliang)

In the Chinese translation, all the personal references “them” are converted into the repetition of its referent “书”, which makes the Chinese translation compact and precise. And the adjective possessive pronoun "their" is omitted in the Chinese translation which is a common feature in Chinese.

\section{DIFFERENCES WITH RESPECT TO SUBSTITUTION}

Whereas the cohesion of reference lies in the semantic level, substitution is used to avoid the repetition of a lexical item through grammatical resources of the language (Bloor and Bloor, 1995: 96). The substitution can be nominal, verbal and clausal. Substitution words have the same function such as "one and ones" for nouns and "do" or "so" as in "do so" or "that and "it" for verbal, nominal, and clausal substitutions (Halliday and Hasan 1976:125-126).

Substitution in English coincide with “...的”, “一样的”,“干，弄”, and “这样” in Chinese. However, in many cases, there is not a one-to-one correspondence in terms of substitution. Comparatively speaking, substitution is more frequently adopted in English than in Chinese, and substitution in English tends to be realized by means of reference or repetition in Chinese. The main reason for this phenomenon is that English emphasizes more in hypotaxis, which is characterized by strict grammatical relationships and converge form. Because substitution is the replacement of a part of a sentence with a substitute word or phrase in the same grammatical slot, substitutions are more extensively used in grammatically strict English. On the other hand, Chinese emphasizes more in parataxis, its elements connected through hidden logic relations more than grammatical relations. Consequently, substitution as a structural link is far less used in Chinese.

Example 3:

ST And therefore, if a man write little, he had need have a great memory; if he confer little, he had need have a present wit; and if he read little, he had need have much cunning, to seem to know that he doth not. (cited from Of Study)

TT: 因此不常做笔记者须记忆力特强, 不常讨论者须天生聪颖，不常读书者须欺世有术，始能无知而显有知。 (translated by Wang Zuoliang)

In Chinese translation, the substitution word "doth" is converted to the repetition of the word “知”, which is rhythmic and clear in Chinese. 


\section{DIFFERENCES WITH RESPECT TO ELLIPSIS}

Ellipsis shares some similarities with substitution which is been described in the above part and both ellipsis and substitution are used to avoid the repetition of certain items or structures. In simple words, substitution refers to the replacement of one item by another while ellipsis refers to the omission of an item. Halliday and Hasan (1976) claim that ellipsis can be seen as a special form of substitution, that is zero substitution.

While English needs some form markers which function as main way of indicating ellipsis because English is a hypotactic language, ellipsis in Chinese is not so restrict grammatically and even logically due to its paratactic language. For instance, in Chinese, when the subject in a sentence or in series of sentences is the same one, it is frequently omitted. However, this type of omission is not correct in English unless they are imperative sentences.

In contrast, English verbs serving as predicates in parallel structure are sometimes omitted to achieve the rhetoric effect, which is ungrammatical in Chinese. Considering this difference between English and Chinese in elliptical structures, translators should make some proper adjustments in translation.

Example 4:

ST: Reading maketh a full man, conference a ready man, and writing an exact man. (cited from Of Study)

TT: 读书使人充实, 讨论使人机智, 笔记使人准确。(translated by Wang Zuoliang)

English is a hypotactic language so the slot between the subject and object is easily recognized and filled by readers in a parallel structure. But in the Chinese translation, the omitted verb is reproduced.

\section{DIFFERENCES WITH RESPECT TO CONJUNCTION}

Conjunction is a cohesive device signaling how a proposition connects to previous discourse. Conjunctive elements are not "devices reaching out to the preceding (or following) text" like reference, substitution and ellipsis. Rather they are cohesive "by virtue of their specific meanings."(Halliday \& Hasan 1976, p.226). In other words, unlike reference, substitution, and ellipsis, the use of conjunction is not to make the text cohesive by referring to the context or by filling structural slots. Instead, conjunction signals the logical relations between sentences, preparing the reader for what to expect. In cohesive relation, conjunction plays an important role not only by establishing a textual and grammatical relation but also semantic relation. Conjunction involves the use of formal markers to relate sentences, clauses and paragraphs to each other. They work as "cohesive ties between clauses or sections of text in such a way as to demonstrate a meaningful pattern between them" (Bloor \& Bloor, 1995, p98). According to Halliday and Hasan (1976), conjunction can be classified into four types: first, additive: and, or. etc.; second, adversative: yet, but, though, etc.; third, causal: then, hence, which, so, therefore, for this reason, as a result, etc.; fourth, temporal: previously, next then, finally, etc.

Because conjunction has its own specific meaning, through these conjunction elements, people can understand the relations between sentences semantically. It is clear that conjunction has the same meaning and function in cohesion in both English and Chinese. Therefore, within a text, a conjunctive item is used in a similar way between sentences or paragraphs in these two languages. But in Chinese, implicit links are also common. "When the relationship between two clauses is not signaled explicitly, the reader must make inference from his/her knowledge of the situation and the context (Li \& Thompson, 1981, p. 641). The absence of explicit markers in Chinese is pervasive, especially in classical Chinese literature. While in English syntax, various conjunctives help to form a complete structure by elements tied together, Chinese syntax is in shorter structures and the conjunctive relations are often embedded through the order in which these elements are formed. Many Chinese idioms are good examples in case, such as 汗流浃背(The sweat broke out all over one's body and trickled down his back), indicating a temporal order, 玩物丧志(one loses his spirit due to seeking too much pleasures), indicating a cause-effect relation, 不进则退(Move forward, or you'll fall behind), indicating a condition-hypothesis relation. In English, many of the implicit linking elements are rendered implicit in the Chinese translation.

Example 5:

ST: So if a man's wit be wandering, let him study the mathematics; for in demonstrations, if his wit be called away never so little, he must begin again. (cited from Of Study)

TT: 如智力不集中, 可令读数学, 盖演题须全神贯注, 稍有分散即须重演。(translated by Wang Zuoliang)

In the Chinese translation, the conjunctions "so" and "if" are omitted, for the logical relations are implied through the word order.

In spite of all the differences, the disparity of conjunction is not absolutely rigid in these two languages. It is relative and flexible. In other words, although explicit conjunctions are more possible in most English texts, implicit conjunctions are also been used in some discourses. Zhu Yongsheng (2001, p.100) claims that the frequency of conjunction in texts concerns the discrepancy of implicitness and explicitness.

\section{DifFERENCES With RESPECT TO LEXICAL COHESION}

Lexical Cohesion is a linguistic device which helps to create unity of text and discourse. In contrast to grammatical cohesion, lexical cohesion "is the cohesive effect achieved by the selection of vocabulary." (Halliday 1976, p. 274). 
According to previous studies of Halliday and Hasan as well as other linguists, lexical cohesion mainly consists of reiteration and co-occurrence with the former one being subdivided into repetitive reiteration and similarity reiteration while the latter one, contextual co-occurrence and collocational co-occurrence. Lexical cohesion is one of the major cohesive devices. Lexical items often connect to form lexical chains in discourse which enables the unity of the context and achieves the coherence of the discourse thereby.

\section{A. Reiteration}

Repetitive reiteration is the mere identical recurrence of a preceding lexical item, so it is the most direct and obvious source of lexical cohesion. It performs the function of conveying rhetorical effect, enhancing expressive force and as well as highlighting the theme of a literary work. Therefore, the repetitive semantic relation with such functions should be retained if there is corresponding lexical relation in Chinese so as to faithfully covey its stylistic significance and coherent effect, making Chinese readers obtain the same perception for such a text. English rarely uses repetition of words to construct a text, so repetition becomes an effective rhetorical device under certain circumstance and it can be seen as a variation for the convention (Wei Zhicheng, 2004). Therefore, once repetition occurs in an English text, it is worth recognizing and reproducing it in Chinese, for there must be literariness or rhetoric effects contained in such a text.

Example 6:

ST: Today, as never before, the fates of men are so intimately linked to one another that a disaster for one is a disaster for everybody. (cited from The Little Virtues)

TT: 当今世界, 人类的命运前所未有的紧密联系在一起。一个人的灾难将是每个人的灾难。(translated by author of this paper)

The repetition of "disaster" foregrounds the rhetoric effects of the text. In the Chinese translation, the repetitive item is retained to convey the semantic meaning.

Compared with the repetitive reiteration stated previously, similarity reiteration, means two or more words are semantically the same or similar but formally different. Similarity reiteration includes synonyms, antonyms, hyponymous words and part whole relation words. In principle similarity reiteration should be retained intact in translation. However, Chinese is different from English in constructing a text-it prefers to use the same word to joint related items. Therefore, it is necessary for E-C translators to convert the semantic relation, from synonymous cohesion into repetitive one for the sake of reproduction of semantic coherence. After all, synonyms have the same referent, thus it is reasonable to make such a conversion.

Example 7:

ST: Lady Catherine had many other questions to ask respecting their journey, and as she did not answer them all herself, attention was necessary, which Elizabeth believed to be lucky for her; or, with a mind so occupied, she might have forgotten where she was. Reflection must be reserved for solitary hours; whenever she was alone, she gave way to it as the greatest relief; and not a day went by without a solitary walk, in which she might indulge in all the delight of unpleasant recollections. (Cited from Pride and Prejudice)

TT: 提到她们的旅程, 凯瑟琳夫人还有许多话要问。由于她不完全是在自问自答, 因此必须留心去听, 伊丽 莎白倒觉得专注于谈话是她的运气, 否则, 她这么心事重重, 一定会忘了自己作客身份呢。心事应在独处时去 想。没有他人在场时, 她就尽情地想心事; 只要独自散步, 她就爱边走边想着一些不愉快的事情, 而且翻来覆 去想个痛快。(translated by Sun Zhili )

In English version, there are four near-synonyms setting up a cohesive chain----“a mind so occupied", "reflection", "it" and "recollection", which contributes the textual meaning that Elizabeth was overwhelmed by her apprehensions. But in the Chinese version two repetitive cohesive chain, namely “心事重重”, “心事”, “想心事” and “边想”, “想个痛 快” are respectively selected to achieve the same semantic effect.

Hyponymy and hypernymy words, the two types of reiteration demonstrate the nature of English as an extensive-vocabulary-used language. For E-C translation, cohesive devices in most cases can be translated directly. However, it should be noted that it is not frequent in Chinese to choose different words to reproduce their English counterparts but make conversions by using vocabulary with overlapping morphemes, especially in general-spercific relation.

Example 8:

ST: Pulling an old envelop from his pocket, he extracted the five hairs he had taken from the old hand of the dead barker. He opened a drawer and took out a small but powerful microscope and arranged the light. Silently he inspected the strands beneath the microscope. Finally he put the instrument away and sat back on the edge of his bunk. (Cited from The Carnival of Death)

$\mathrm{TT}$ : 他从口袋里掏出个旧信封, 从里面取出 5 根头发, 那是从死去的伙计手里发现的。他打开抽屉, 拿出一 架小巧精细的显微镜, 调整光后就一声不吭地研究起显微镜下的发丝来。终于他把显微镜放在一边, 又坐回床 边。(translated by author of this paper)

In the sentence, "strands" and "hairs" constitute a general-specific relation, but it is idiomatic and natural to convey it by the repetition of “头发". Likewise, “microscope" belongs to the category of "instrument" because it is a tool or 
device used for a particular task, especially for delicate or scientific work. In the Chinese translation, “显微镜” is repeated to achieve the same coherence, for repetition is a main device in lexical cohesion whereas English discourse usually avoid the repetition of the same word, in stead, discourse cohesion relies more on the use of synonyms, hyponyms, general word or other cohesive devices.

\section{B. Co-occurence}

Co-occurrence cohesion in the text plays its vital role in setting up certain network through the semantic links among lexical items co-occurring. The vertical lexical chains made of contextually co-occurring lexical items and the horizontal chains made of collocational lexical items connect to form lexical chains in discourse, which enables the unity of the context and achieves the coherence of the discourse. English is a language in which polysemous words predominate, so lexical chains in a text serves vital coherent functions of removing ambiguity, identifying the accurate meaning of polysemous words and restoring the semantic expression of the source text.

Example 9:

ST: A continuous concomitant of contact between two mutually incomprehensible tongues and one that doesn't lead either to suppression or extension of either their is translation.(Cited from Xu Lina)

TT: 语言不通的人们, 在其交际过程中，始终离不开一种媒介，这种既不缩小又不扩大源语的媒介就叫做翻 译。(Cited from Xu Lina)

The word concomitant is defined in dictionary as "something that happens with something eles and is connected with it. Due to the lexical chains formed here as "contact-tongues-translation", the definite meaning of it narrows down to “媒介” when translated into Chinese.

\section{CONCLUSION}

Devices in Halliday and Hason's model (1976), namely, reference, substitution, ellipsis, conjunction and lexical devices are present in both English and Chinese. However, the importance attached to various types of devices seems to be different. As for English and Chinese, some cohesive devices might be less used in one language or even be avoided, while they are more frequently used in the other language. The reasons lie in that English and Chinese belong to different language systems. English is a hypotactic-oriented language, featured by the tightly-knitted structures. Both words and sentences are supposed to represent clear logic relations. Discourse understanding is realized by analyzing the precise language with rigorous forms and by probing the internal relation between words and sentences. Therefore, English discourse coherence is realized by certain explicit cohesive devices. On the contrary, Chinese is paratactic-oriented, laying less emphasis on the cohesive forms, thus, the sentence structures are more flexible. Discourse understanding depends more on the reader's knowledge of the context and the real world, therefore, Chinese discourse coherence is sometimes not realized by explicit cohesive devices but relies on implicit cohesive mechanisms. The internal semantic relevance, implicit logic relations and reader's reasoning contribute to the coherence of Chinese discourse. Thus, it is of great value for translators to be aware of the different application of cohesive devices to achieve coherence in English and Chinese translations.

\section{REFERENCES}

[1] Bloor.T.\& Bloor. M (1995). The functional analysis of English: a Hallidayan approach. London: Arnold, 98.

[2] Chomsky. (1981). Lectures on Government and Binding: The Pisa Lectures. Holland: Foris Publications.

[3] Francis Bacon. (2007). Essays and Ancient Fables of Francis Bacon. Montana: Kessinger Publishing Company.

[4] Hadley, I.L. (1987). Understanding Cohesion—_-Some Practical Teaching Implications. Literacy, 21(2), 106-114

[5] Halliday, M. A. K., \& Hasan, R. (1976). Cohesion in English. London: Longman Group.

[6] Hatim, B. \& Mason, I. (2001) Discourse and the Translator. Shanghai: Shanghai Foreign Language Education Press.

[7] HU, Z. L. (1994). Discourse cohesion and coherence. Shanghai: Shanghai Foreign Language Education Press.

[8] Jane Austen. (1983).Pride and Prejudice. New York: Bantam Books Ltd.

[9] Li, Charles N. and Sandra A. Thompson. (1981). Mandarin Chinese: A Functional Reference Grammar. Berkeley and Los Angeles: University of Chicago Press, 641-659.

[10] Newark, P. (1987). A Textbook of Translation. Hemel Hempstead: Prentice Hall, 295.

[11] PAN Guowen. (1997). Contrastive studies of Chinese and English. Beijing: Beijing Language and Culture University Press.

[12] Sun Zhili. (2010). Pride and Prejudice. Jiangsu: Yilin Publishing House.

[13] Wang Zuoliang. (2013). Bacon's Essays. Xi'an: Xi'an Jiaotong University Press.

[14] Wei Zhicheng. (2004). A course of comparative translation from English into Chinese. Beijing: Tsinghua University Publishing House.

[15] Xu Lina. (2012). On repetition as a cohesive devices on translaton. Shandong Foreign Language Teaching Journal. 151(6), 86-95.

[16] Zhao Yuanren. (1979). A Grammar of Spoken Chinese. Beijing: Businesses Press, 45.

[17] Zhu Y.S, Zheng L.X, \& Miao. X.W. (2001). A contrastive study of cohesion in English and Chinese. Shanghai: Shanghai Foreign Language Education Press.96-100. 
Jing Wu was born in Jinan, China in 1977. She received her M.A. degree in linguistics from Shandong Normal University, China in 2004. She is currently a lecturer in Foreign Languages School, Qingdao University of Science and Technology, Qingdao, China. Her research interests include translation theories and practice and cross-cultural communication. She has translated more than 10 books from English to Chinese. 